\title{
Embryology and adult urology - Not always mutually exclusive: A case report on true hermaphroditism at an adult urology clinic
}

\author{
Rafal Turo, MD; Laura F. Derbyshire, MD; ${ }^{\dagger}$ Michal Smolski, MD; Gerald N. Collins, MD; Niall Lynch, MD; \\ Maryna Lewinski, MD; Richard J. Brough, MD; ${ }^{\dagger}$ Andrew M. Sinclair, MD ${ }^{\dagger}$
}

*Urology Department, St. James's University Hospital, Leeds, West Yorkshire, United Kingdom; †Urology Department, Stepping Hill Hospital, Stockport, Cheshire; §Radiology Department, Stepping Hill Hospital, Stockport, Cheshire

Cite as: Can Urol Assoc J 2014;8(9-10):e650-3. http://dx.doi.org/10.5489/cuaj.2035 Published online September 9, 2014.

\section{Abstract}

True hermaphrodite $(\mathrm{TH})$ is one of the rarest varieties of disorders of sexual differentiation. Most patients present early in the life and are managed by pediatricians. We present a rare case of an adult TH which was first diagnosed by a urologist. We discuss the pathology of $\mathrm{TH}$ and its clinical relevance. Knowledge and awareness of embryology are vital to all specialties.

\section{Case report}

A 50-year-old male presented to the urology outpatient clinic with a 6-month history of frequency, nocturia, urgency, urge incontinence and poor flow. His medical history included surgery as a child (reason and type of surgery unknown) and non-Hodgkin's lymphoma (NHL), with lumpectomy and radiotherapy in 1992. He is married, with normal erections and ejaculations; he has no children. He had always attributed his infertility to the radiotherapy for his NHL.

On examination he had a Pfannenstiel scar. External genitalia showed a hooded foreskin, a coronal urethral meatus and a midline scrotal and perineal scar. There was no right testicle and a small atrophic left testicle. His prostatic fossa felt empty on rectal examination. The flow rate showed a maximum flow rate (Qmax) of only $7.1 \mathrm{~mL} / \mathrm{sec}$ and a prolonged trace. His testosterone levels were normal and the only abnormality on his hormone profile was a raised follicle-stimulating hormone $(\mathrm{FSH})$. His prostate-specific antigen (PSA) was unrecordable.

He failed to respond to anticholinergics. At flexible cystoscopy, the penile urethra was normal. We were unable to pass the scope through the bulbar urethra, due to a presumed stricture. At rigid cystoscopy, under general anesthesia, we again were unable to navigate beyond the proximal bulbar urethra as the surgeon was unable to identify a lumen to the bladder, even with the use of a guide wire.

He was then referred to a reconstructive specialist. A urethrogram showed a beaded distal penile urethra and a normal size bulbar urethra communicating posteriorly with a redundant cavity (Fig. 1). It also demonstrated flow of contrast into the bladder. On voiding there was complete bladder emptying, but significant retention of contrast within the cavity, which was situated above the external sphincter (Fig. 2).

A subsequent magnetic resonance imaging (MRI) scan showed that the redundant cavity was a hypoplastic vagina inserting into the posterior urethra. There was no prostate and an absent right testis (Fig. 3). He underwent a urethroscopy using a $7.5 \mathrm{Fr}$ pediatric cystoscope. At the bulbar urethra, in place of the verumontanum, there was a lumen of about $24 \mathrm{Fr}$ into the redundant vagina. This was displacing a small urethral lumen superiorly, explaining the inability to enter the bladder previously. A guide wire was placed through the small urethra into the bladder and S Curve Urethral Dilators (Cook Medical, Inc.) were used to widen the strictured lumen. The bladder was normal and a urethral catheter was inserted over the guide wire. He had a successful trial without a catheter 5 days postoperatively. Three months later his urinary symptoms had completely resolved, with an excellent flow.

\section{Discussion}

Early subspecialization has led to a reduction in the modern urologist's knowledge and experience in pediatric urology. Subjects, such as embryology and disorders of sex development (DSD), are learned for exam purposes and not used regularly in clinical practice. Many trainees question the appropriateness of these topics in the urology syllabus, and their relevance to adult urological practice. This case reinforces our view that knowledge and awareness of embryology and 


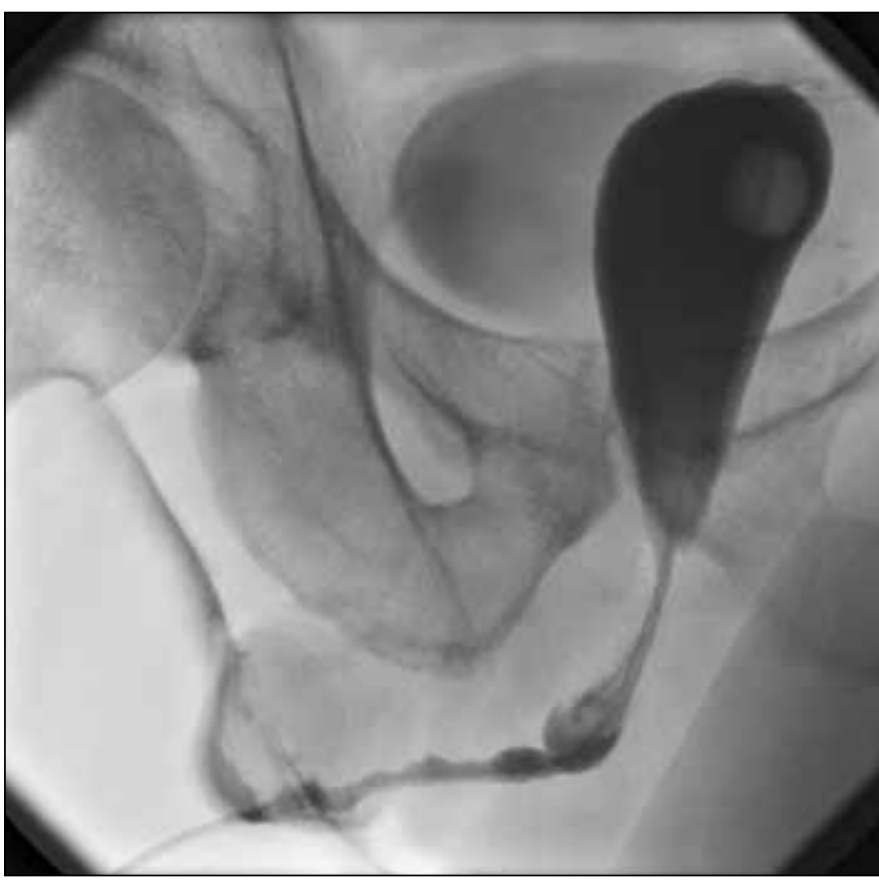

Fig. 1. Voiding cystourethrogram showing a beaded distal penile urethra and a normal size bulbar urethra communicating posteriorly with a redundant cavity.

the resulting abnormalities are vital; we discuss the pathology of true hermaphroditism $(\mathrm{TH})$ and its clinical relevance.

TH or ovotesticular DSD describes individuals who have both testicular and ovarian tissue. This may take the form of one ovary and one testis or, more commonly, one or two ovotestes. Most patients with TH have ambiguous external genitalia, masculinized to variable degrees, although occasionally completely normal appearing mixed male and female genitalia have been reported. ${ }^{1}$ Overall, $75 \%$ of patients with $\mathrm{TH}$ are raised as male; in $80 \%$ of these, chordee, hypospadias and cryptorchidism can be seen. ${ }^{2,3}$ In the $25 \%$ raised as female, clitoromegaly can be present. Almost all patients have a urogenital sinus remnant, with most also having a uterus.

When karyotyped, more than $60 \%$ of these individuals are $46 \mathrm{XX}$; about $33 \%$ are mosaics with a second cell line containing a $\mathrm{Y}$ chromosome, and only $7 \%$ are $46 \mathrm{XY}$. In our patient, no information was available on chromosomal arrangement. The exact genetic mechanism for this disorder is unclear and several hypotheses have been proposed. Ortenberg and colleagues ${ }^{4}$ found somatic mosaicism caused by an SRY gene in all individuals studied. Chimerism could also be caused by fusion of the polar body and an ovum, double fertilization, fusion of two nuclei or as a result of hidden mosaicism with a $Y$ cell line. Other studies support somatic gene mutation or partial gonadal dysgenesis as the responsible mechanism. ${ }^{5,6}$

Differentiation of the internal organs and ducts is extremely variable. However, the importance of recognizing $\mathrm{TH}$

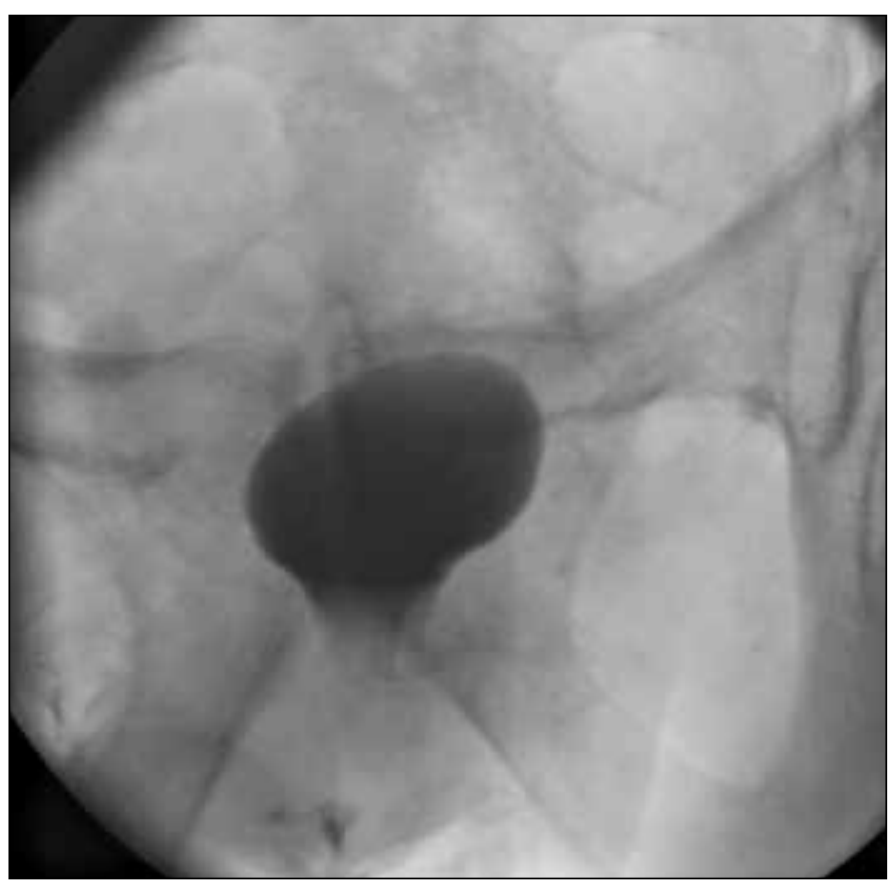

Fig. 2. Voiding cystourethrogram showing a complete bladder emptying but significant retention of contrast within the cavity, which was situated above the external sphincter.

is that although the external genitalia may be ambiguous or normal, these individuals can have complete internal organs. Full development of the internal genitalia depends on the predominant function of that ipsilateral gonad, ${ }^{7,8}$ so that fallopian tubes are present with an ipsilateral ovary and likewise a vas deferens is always present adjacent to a testis. ${ }^{5}$ An ovotestis contains both ovarian (found in the poles) and testicular tissue (found centrally). ${ }^{9}$ If there is a testes or an ovotestis with predominant testicular function, the testes is likely to descend; ${ }^{10}$ commonly, however, the testicular portion of the ovotestis is dysgenetic.

In normal anatomy, the verumontanum or seminal colliculus is a protrusion found on the posterior wall of the prostatic urethra. It contains a central blind ending opening, the prostatic utricle, and the two lateral openings of the ejaculatory ducts. The differentiation of the sex gonads depends on the presence, of lack of, a Y chromosome, and a functioning SRY gene. The development of the internal genitalia is dependent on the production, or lack of, of hormones from the foetal testis; both testosterone from the Leydig cells and anti-Mullerian hormone $(\mathrm{AMH})$ from the embryonic Sertoli cells are needed. Testosterone maintains the mesonephric ducts and later causes the development of the accessory glands (seminal vesicle, prostate and paraurethral glands) and their connection to the urethra. AMH causes degeneration of the paramesonephric ducts; the prostatic utricle is the remnant of these ducts in males. In females, the lack of these hormones causes the opposite; the mes- 


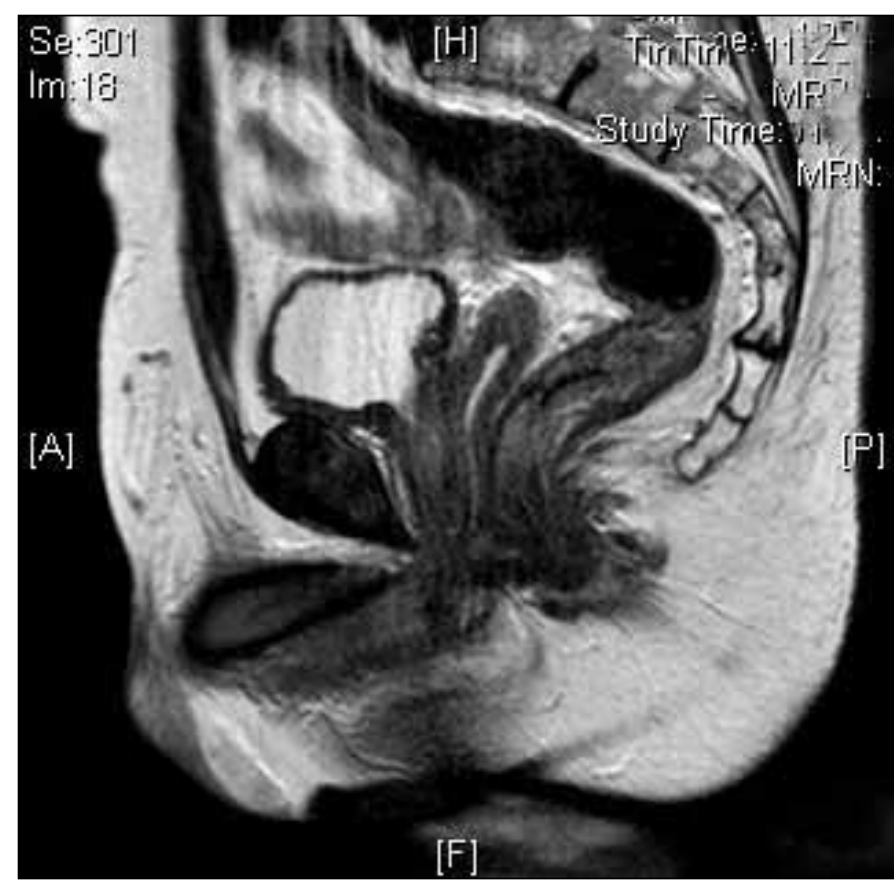

Fig. 3. Magnetic resonance imaging showing a redundant cavity to be a hypoplastic vagina inserting into the posterior urethra. There was no prostate.

onephric ducts degenerate and the paramesonephric ducts continue to grown, fuse in the midline, and ultimately differentiate into the fallopian tubes, uterus, cervix and vagina. Differentiation of the external genitalia occurs at a similar time, again dependant on the presence of testosterone; the genital tubercle and the labioscrotal fold form the penis and scrotum in males, in the presence of testosterone. The movement of testis into the scrotum is under Leydig cell control around week 12, then testosterone from week 25 .

On urethroscopy in this patient, where it was expected to see the verumontanum, there was redundant cavity; this was described on MRI to be a redundant vagina. There was also no prostate gland seen, and although a left-sided testicle was present, the right scrotum was empty. The external genitalia grossly appeared to be male, with hypospadias, although there had been some previous surgery. Although the exact course of development in this man was difficult to accurately determine, there has clearly been testosterone present to form his left male gonad and external genitalia. The hypospadias, lack of prostate and redundant vagina would suggest that the testosterone levels were not sufficient to induce full gland development, or full paramesonephric duct degradation. Based on the literature, his left-sided gonad was likely a complete testis, hence its full descent. It is also likely that the associated vas deferens was complete. The right side was more difficult to predict - the previous surgery could have been to remove an undescended testis, an ovary (and therefore associated female tubes) or an ovatestis.
Although there is limited literature surrounding potency and fertility in $\mathrm{TH}$, it is reported as possible. ${ }^{11}$ Our patient had normal sexual function, but no children.

Patients brought up as male after sex assignment surgery require careful testicular tumour surveillance. The overall incidence of gonadal tumours is about $3 \%$ in individuals with $46 \mathrm{XY}$ karyotype and very rare incidence in patients in $46 \mathrm{XX} .{ }^{12}$ Commonly described tumours include dysgerminoma and gonadoblastoma. ${ }^{13}$ Our patient was unaware that he had ambiguous genitalia prior to this presentation with lower urinary tract symptoms and so he had never been counselled about the increased risk of testicular cancer and the need for regular surveillance. He has since been informed of the need for regular testicular examination and has been referred for surveillance ultrasounds.

In this case, the patient's medical history of TH was not known when the patient was initially seen. The inability to perform the cystoscopy by an experienced urologist led to further questioning and referral to the reconstructive specialist. Imaging was then organized to guide further management, which was interpreted with the help of an experienced uro-radiologist. The preoperative planning allowed us to successfully map, access and explore the urethra.

\section{Conclusion}

The diagnosis and management of DSD patients is complex and should be under the care of specialist pediatric and adolescent teams. However, the awareness and recognition of undiagnosed DSD are vital to all urologists, especially when possible abnormalities of anatomy are encountered during routine investigations for common symptoms. A lower threshold for suspicion should be considered if there is unexplained childhood surgery. An understanding of urological embryology certainly helped us manage this patient.

Competing interests: Dr. Turo, Dr. Derbyshire, Dr. Smolski, Dr. Collins, Dr. Lynch, Dr. Lewinski, Dr. Brough and Dr. Sinclair all declare no competing financial or personal interests.

This paper has been peer-reviewed.

\section{References}

1. Iqbal MZ, Jam MR, Saleem M, et al. True hermaphrodite: A case report. APSP J Case Rep 2011;2:16.

2. Luks Fl, Hansbrough F, Klotz DH Jr, et al. Early gender assignment in true hermaphroditism. J Ped Surg 1988;23:1122-6. http://dx.doi.org/10.1016/S0022-3468(88)80326-9

3. Olsson CA, Tessier PA, Brown ML, et al. True hermaphroditism. J Urol 1971;105:586-90.

4. Ortenberg J, Oddoux C, Craver R, et al. SRY gene expression in the ovotestes of XX true hermaphrodites. J Urol 2002;167:1828-31. http://dx.doi.org/10.1016/S0022-5347(05)65242-1

5. Berkovitz GD, Fechner PY, Zacur HW, et al. Clinical and pathologic spectrum of $46, X Y$ gonadal dysgenesis: Its relevance to the understanding of sex differentiation. Medicine 1991;70:375-83. http://dx.doi. org/10.1097/00005792-199111000-00003 
6. Hadjiathanasiou CG, Brauner R, Lortat-Jacob $S$, et al. True hermaphroditism: Genetic variants and clinical management. J Ped 1994;125:738-44. http://dx.doi.org/10.1016/S0022-3476(06)80172-1

7. Moshiri M, Chapman T, Fechner PY, et al. Evaluation and management of disorders of sex development: Multidisciplinary approach to a complex diagnosis. Radiographics 2012;32:1599-618. http://dx.doi. org/10.1148/rg.326125507

8. Nabhan ZM, Lee PA. Disorders of sex development. Curr Opin Obstet Gynecol 2007;19:440-5. http:// dx.doi.org/10.1097/GC0.0b013e3282eeb13d

9. Nihoul-Fekete C, Lortat-Jacob $S$, Cachin 0 , et al. Preservation of gonadal function in true hermaphroditism. J Ped Surg 1984;19:50-5. http://dx.doi.org/10.1016/S0022-3468(84)80015-9

10. Karam JA, Baker LA. Images in clinical medicine. True hermaphroditism. N Engl J Med 2004;350:393 http://dx.doi.org/10.1056/NEJMicm030685
11. van Niekerk WA. True hermaphroditism: An analytic review with a report of 3 new cases. Am J Obstet Gynecol 1976;126:890-907.

12. Wein AJ, Novick AC, Partin AW, et al. editors. Campbell-Walsh Urology. 10th Edition; 2011.

13. Verp MS, Simpson JL. Abnormal sexual differentiation and neoplasia. Cancer Genet Cytogenet 1987;25:191-218. http://dx.doi.org/10.1016/0165-4608(87)90180-4

Correspondence: Mr. Rafal Turo, Department of Urology, Stepping Hill Hospital, United Kingdom; rturo7@yahoo.com 